\title{
DESIGN OF A QUADRUPED ROBOT AND ITS INVERSE KINEMATICS
}

\section{PALIVELA ARUN KUMAR ${ }^{1} \&$ YEOLE SHIVRAJ NARAYAN ${ }^{2}$}

${ }^{1}$ M.Tech. (Automation), VNR Vignana Jyothi Institute of Engineering and

Technology, Hyderabad, Telangana, India

${ }^{2}$ Professor, Mechanical Engineering, VNR Vignana Jyothi Institute of Engineering and

Technology, Hyderabad, Telangana, India

\begin{abstract}
Mobile robots have many abilities, of which the most unique one is the mobility. The terrain over which, these robots must be able to move is often uneven, slippery or muddy, which gives rise to many challenges, particularly stability. Two of the most common methods for robot mobility are wheels and legs. The necessity of legged robots is increasing day by day, as compared to the wheeled robots. Legged robots are more advantageous and versatile than wheeled robots, on uneven terrain such as military operations, remote locations, dangerous environments, excavation and construction works and medical applications. However, achieving the perfect locomotion and mobility of legged robots, on any type of terrain is the area of current research. This paper presents, design of a quadruped robot having four legs, but based on human leg structure. An attempt was also made, to perform inverse kinematic analysis on the design for validation. The paper also explains the procedure of designing a quadruped robot and the parameters involved in it.

KEYWORDS: Quadruped Robot, Legged Robots, Inverse Kinematics, Robo-Analyser Software \& DH-Parameters
\end{abstract}

Received: Jun 30, 2017; Accepted: Jul 18, 2017; Published: Jul 24, 2017; Paper Id.: IJMPERDAUG201725

\section{INTRODUCTION}

Legged robots are more advantageous, than wheeled robots in uneven terrain. Wheeled robots need a fixed terrain to move, but legged robots can move on uneven terrain with ease. Designing of legged robots involves various parameters, such as leg structure, leg kinematics, leg joints, actuators, stability and motion control. Rashid et al. (2012) designed and developed a Hexapod robot with maneuverable wheel for ease of movement on either the flat surface or the inclined surface. The Hexapod robot uses maneuverable wheels, to move on a flat surface and legs, to climb the inclined surfaces. The decision for using wheels or legs is based on the sensor devices and the algorithm, developed at the controller attached to the robot. Giuseppe Carbone et al. (2005) presented a survey of legged robots of current solutions and prototypes, with illustrated fundamental characteristics and problems for their design, operations, along with insights on low cost, easy operation solution that can really make walking machines available to non-expert users for many applications. Bhawana et al. (2014) designed and developed a legged robot for military purpose application, to protect the army. The method involves two-legged biped walking robot, using parallel leg mechanism. Seong Chiun Lim et al. (2012), designed a prototype robot which can assist the humans in hazardous environment. The robot is developed to provide a test bed for the physical locomotion, that is used to control the robot movements, such as moving forward, backward, turn left and right, get up from front and back and roller over from left and right. It describes the procedure of 
building a bipedal robot and the step movements.

\section{SELECTION OF A LEGGED ROBOT}

Designing a legged robot is very complicated than a wheeled robot. There are different types of the leg structures for different legged robots. A bipedal robot follows the human leg structure as a base, while quadruped robot uses mammal leg structure and hexapod robot uses insect leg structure. Leg of a humanoid robot has three joints, without considering the foot as it consists of many joints. A human leg structure can achieve 41 degrees of freedom, whereas a mammal leg structure can achieve up to 12 degrees of freedom and insects can achieve up to 18 degrees of freedom. Selection of appropriate type of robot configuration is of prime importance, for any specific application. Table 1, displays the criteria for the selection of a robot's configuration.

Table 1: Selection of Robot Configuration

\begin{tabular}{|l|l|l|l|}
\hline \multicolumn{1}{|c|}{ Criteria } & \multicolumn{1}{c|}{ Bipedal } & \multicolumn{1}{c|}{ Quadruped } & \multicolumn{1}{c|}{ Hexapod } \\
\hline Natural Design & Human & Mammals & Insects \\
\hline $\begin{array}{l}\text { Conceptual } \\
\text { design }\end{array}$ & & Rectangular, circular frames & $\begin{array}{l}\text { Rectangular, circular, } \\
\text { hexagonal frames }\end{array}$ \\
\hline DOF & $2-41$ & $2-12$ & $2-12$ \\
\hline Actuators & Servos (electrical ) & Servos (electrical ) & Servos (electrical ) \\
\hline $\begin{array}{l}\text { Number of } \\
\text { actuators }\end{array}$ & $\begin{array}{l}\text { Minimum of 3 per leg, } \\
\text { Total 6 actuators }\end{array}$ & $\begin{array}{l}\text { Minimum 3 per leg, } \\
\text { Total 12 actuators }\end{array}$ & $\begin{array}{l}\text { Minimum 3 per leg, } \\
\text { Total 18 actuators }\end{array}$ \\
\hline Controllers & $\begin{array}{l}\text { ATMEGA, Arduino, Maestro } \\
\text { Servo controllers, etc. }\end{array}$ & $\begin{array}{l}\text { ATMEGA, Arduino, Maestro } \\
\text { Servo controller }\end{array}$ & $\begin{array}{l}\text { ATMEGA, Arduino, Maestro } \\
\text { Servo controller }\end{array}$ \\
\hline Power & Battery(12v) & Battery(12v) & Battery(12v) \\
\hline Sensors & 2 Force,1 Gyroscope sensors & 3 Force sensors & 6 Force sensors \\
\hline
\end{tabular}

Bipedal robots have a higher degree of freedom (DOF), as compared to the quadruped and hexapod robots, and the number of actuators in a bipedal robot is comparatively less than quadruped and hexapod robots. Thus, use of the bipedal leg structure of a quadruped robot, reduces its number of components. Using the same in hexapod configuration, would make the design complex.

\section{CONCEPTUAL DESIGNS}

So far, every design of legged robots is taken from nature such as, bipedal robots represent human leg structure, quadruped robots represent the mammal leg structure and hexapod robots represent the insect leg structure. In this work, a new approach is proposed in the design, by considering the human leg structure for a quadruped robot. Because the human leg structure has three joints that is thigh joint, knee joint and foot joint, whereas mammals have more number of joints. Use of human leg structure will reduce the number of joints and increase the performance of the robot. Bipedal robot uses symmetric gaits for walking, which are more stable than asymmetric gaits. Therefore, higher degree of freedom can be achieved in quadruped robots.

In order to make a full proof and accurate working robot, it is important to prepare a sound design which starts with the conceptual design stage. A conceptual design is prepared based on thorough analysis of parameters, which are shown in Table 2. Parameters like the construction, control, stability, programming, weight, application, etc. are studied for bipedal, quadruped and Hexapod robot configurations.

As shown in Table 2, construction of a bipedal robot leg is easy, as compared to quadruped and hexapod robot. Use of a bipedal leg structure for quadruped robot, reduces the complexity of construction and can produce symmetric 
gaits, which are more stable than asymmetric gaits, hence is selected as the leg structure in the proposed quadruped robot.

Table 2: Comparison of Parameters for Conceptual Design

\begin{tabular}{|l|l|l|l|}
\hline \multicolumn{1}{|c|}{ Parameters } & \multicolumn{1}{c|}{ Bipedal } & \multicolumn{1}{c|}{ Quadruped } & \multicolumn{1}{c|}{ Hexapod } \\
\hline Construction & Easy & Complex & Complex \\
\hline Control & Difficult & Easy & Easy \\
\hline Stability & Difficult & Neutral & Easy \\
\hline Programming & Complex & Less Complex than hexapod & Complex \\
\hline Application compatibility & Difficult & Neutral & Easy \\
\hline Weight & Lesser than both & Less than hexapod & More weight \\
\hline Modelling \& Analysis & Easy & Neutral & Difficult \\
\hline Kinematic Analysis & Difficult & Neutral & Neutral \\
\hline
\end{tabular}

Figure 1 displays the leg structures of mammals like monkey, dog, sheep, and horse including human being. These structures show the increasing complexity involved in various mammals. Figure also presents the conceptual representation of these leg structures to be used in a robot leg design.

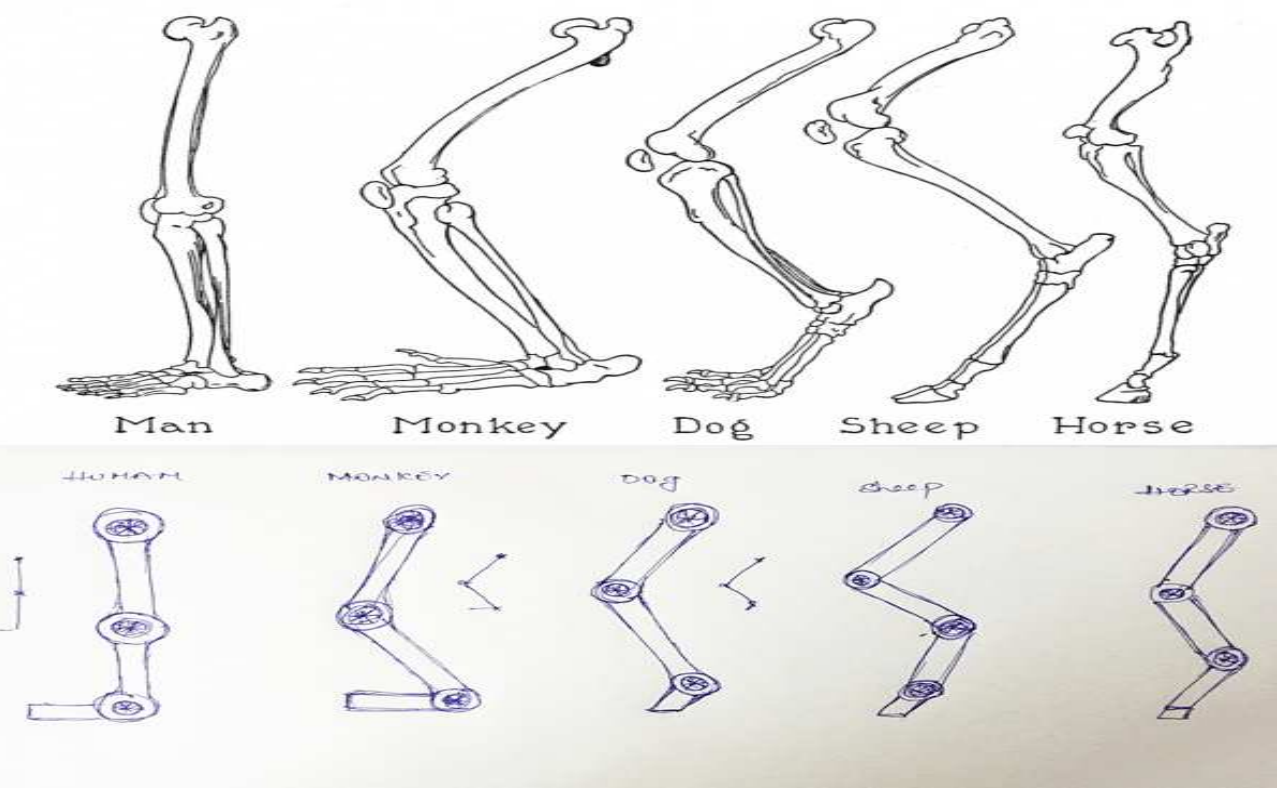

Figure 1: Conceptual Design of Leg Structure in Mammals

Amongst the leg structures of mammals shown in Figure 1, the locomotion style of humans and horses is same i.e., walking. Hence, a comparative study is made between various parameters to make a selection between human leg and horse leg locomotion in the proposed robot, as shown in Table 3.

Table 3: Difference between Human and Horse Leg Parameters

\begin{tabular}{|l|c|c|}
\hline \multicolumn{1}{|c|}{ Parameters } & Human & \multicolumn{1}{c|}{ Horse } \\
\hline Locomotion & Walking & Walking \\
\hline Terrain & Uneven & Uneven \\
\hline Average walking speed & $5 \mathrm{~km} / \mathrm{hr}$. & $6.4 \mathrm{~km} / \mathrm{hr}$. \\
\hline No of links & 2 & 3 \\
\hline No of joints & 3 & 4 \\
\hline Number of actuators & 2 & 3 \\
\hline
\end{tabular}

Different conceptual design models have been prepared with different aspects, criteria, specifications, shapes, advantages and disadvantages. The specifications of the robots cover a few main aspects such as, the amount of motors 
used, legs, joints and links, which are shown in Table 4.

Table 4: Conceptual Designs of Quadruped Robot

\begin{tabular}{|c|c|c|}
\hline S. No. & Designs & Specifications \\
\hline 1 & & $\begin{array}{ll}\text { - } & 12 \text { servomotors } \\
\text { - } & \text { Servo motors } \\
\text { - } & \text { Three joints and Four links } \\
\text { - } & \text { Human leg structure } \\
\text { - } & \text { Made of aluminium joints readily available in market. }\end{array}$ \\
\hline 2 & & $\begin{array}{ll}- & 8 \text { servo motors } \\
- & \text { Servo motors } \\
- & 2 \text { joints and } 3 \text { link } \\
- & \text { Human leg structure } \\
- & \text { Made of aluminium joints readily available in market. }\end{array}$ \\
\hline 3 & & $\begin{array}{ll}- & 12 \text { servomotors } \\
\text { - } & \text { Servo motors } \\
\text { - } & \text { Three joints and } 4 \text { links } \\
\text { - } & \text { Human leg structure } \\
& \text { Made of aluminium joints readily available in market. }\end{array}$ \\
\hline 4 & & $\begin{array}{ll}- & 12 \text { actuators } \\
- & \text { DC motors for actuators with gear box } \\
\text { - } & \text { Mammal leg structure } \\
\text { - } & \text { Three joints and } 4 \text { links } \\
\text { Components are made of fibre glass and aluminium plates }\end{array}$ \\
\hline 5 & & $\begin{array}{ll}- & 8 \text { actuators } \\
- & \text { DC motors with gear box } \\
- & \text { Human leg structure } \\
- & \text { Two joints and } 3 \text { links } \\
- & \text { Components are made of fibre glass }\end{array}$ \\
\hline
\end{tabular}

Table 5 shows the characteristics of the conceptual designs prepared in terms of size, weight, actuators and material.

Table 5: Characteristics of Conceptual Designs of Quadruped Robot

\begin{tabular}{|c|c|c|l|l|}
\hline Design & Size $[\mathrm{m}]$ & Weight $[\mathrm{kg}]$ & Actuators & \multicolumn{1}{|c|}{ Material } \\
\hline 1 & $3.0 \times 1.5 \times 2.0$ & 1 & Servo & Aluminium \\
\hline 2 & $2.5 \times 1.5 \times 1.6$ & 0.8 & Servo & Aluminium \\
\hline 3 & $3.0 \times 1.5 \times 2.4$ & 1.2 & Servo & Aluminium \\
\hline 4 & $3.0 \times 1.5 \times 2.0$ & 3 & DC motor & Fibre glass \\
\hline 5 & $3.0 \times 1.5 \times 1.6$ & 2.5 & DC motor & Fibre glass \\
\hline
\end{tabular}

\section{SELECTION OF QUADRUPED ROBOT DESIGN AND ITS MODELING}

It is important to select the best design for a quadruped robot. Out of the five designs mentioned in Table 4 and 5 , one of the best designs has been selected before making the model in detail. Third design has been selected for further 
work because the design is less complex and more reliable than the other designs. It can control the foot joint which improves the gait and helps in obtaining better stability. Controlling the foot joint also avoids the collisions of two legs during movement. Modelling of the robot is done using the Creo software which is used for 3D modelling. By using coordinate system, individual components have been modelled in software and assembled together.

\section{KINEMATICS OF QUADRUPED ROBOT}

Kinematics is the study of the robot movements with regards to a reference system in the analytical description of the spatial movement of the robot such as the positions and orientations of the robot final links and the values of their joint co-ordinates.

\section{Types of Kinematics}

- $\quad$ Direct kinematics

- Inverse kinematics

The direct kinematics consist of robot positions and orientation with regard to a reference coordinate system, resolves the values of each link and the geometric parameters of the robot elements. In other words, for the solution of each link co-ordinates, the final link values will be deduced. Also, it is used to find the position and orientation of the robot using the geometric relations. The inverse kinematics consist on determination of the robot configurations that should adopt the robot at each link to reach the desired position and orientation for the final link.

Table 6: Types of kinematics

\begin{tabular}{|l|l|l|}
\hline Type of Kinematics & \multicolumn{1}{|c|}{ Having } & \multicolumn{1}{c|}{ Objective } \\
\hline Direct & Each joint coordinate & $\begin{array}{l}\text { Finds position and orientation of } \\
\text { each joint at the final robot link }\end{array}$ \\
\hline Inverse & $\begin{array}{l}\text { Position and orientation of } \\
\text { the final robot link }\end{array}$ & Finds each joint coordinate. \\
\hline
\end{tabular}

\section{DENVAIT HARTENBERG METHOD (D-H)}

D-H describes a process for performing robot kinematics and represents its motions. The method works with the quadruped system $\left\{\alpha_{\mathrm{i}}, \mathrm{a}_{\mathrm{i}}, \mathrm{d}_{\mathrm{i}}, \theta_{\mathrm{i}}\right\}$ and is labelled an orthonormal (x, y, and $\mathrm{z}$ ) coordinate system to each robot joint. Relating this way, each joint reference system to the next and forms a complete robot geometry representation.

\section{D-H Notation}

Robots are generally made up of links that are connected by joint to their preceding and subsequent link. The origin here is the base reference coordinate system. Joints could be rotational or translation. Each joint has one degree of freedom. Therefore, a concatenation of $n+l$ links by $n$ joints means the system has $n$ degrees of freedom.

With the definition of fixed and variable kinematic parameters for each link, kinematic models can be defined. This model is the analytical description of the spatial geometry of motion of the manipulator with respect to a fixed (inertial) reference frame, as a function of time. In particular, the relation between the joint-variables and the position and orientation of the end-effector is the kinematic model. It is required to control position and orientation of the end-effector, in $3 \mathrm{D}$ space, so that it can follow a defined trajectory or manipulate objects in the workspace. 


\section{D-H Representation of the Model}

The D-H representation is a simple way of representing the links and joints of the leg which helps in solving the kinematics. It consists of four parameters i.e., link length, link twist, joint distance and joint angle. A 3R (RRR) manipulator having 3 degrees of freedom is used. It consists of $3+1=4$ links which includes base joint. D-H representation and parameters for the 3-DOF leg is shown in Figure 2 and Table 3 respectively.

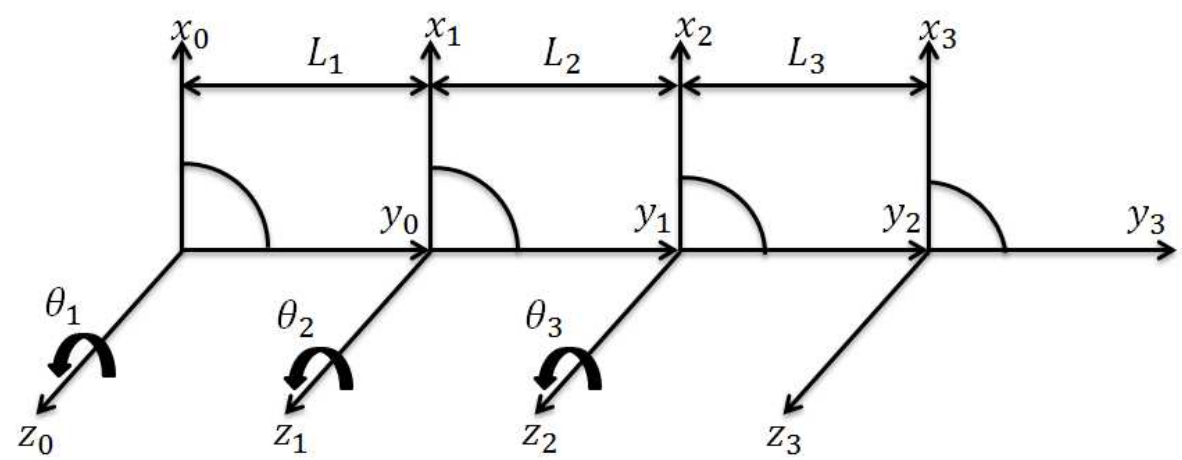

Figure 2: D-H Representation of the Robot Leg

Table 7: D-H Parameters for Robot Leg

\begin{tabular}{|c|c|c|c|c|c|c|c|}
\hline Link i & $\begin{array}{c}\text { Link } \\
\text { Length } \mathbf{a}_{\mathbf{i}} \\
(\mathbf{m m})\end{array}$ & $\begin{array}{c}\text { Link } \\
\mathbf{T w i s t} \boldsymbol{\alpha}_{\mathbf{i}} \\
(\mathbf{m m})\end{array}$ & $\begin{array}{c}\text { Joint } \\
\text { Distance } \\
\mathbf{d}_{\mathbf{i}}(\mathbf{m m})\end{array}$ & $\begin{array}{c}\text { Joint } \\
\text { Angle } \boldsymbol{\theta}_{\mathbf{i}} \\
(\text { Degrees })\end{array}$ & $\begin{array}{c}\text { Displacement } \\
\text { Variable } \mathbf{q}_{\mathbf{i}} \\
\text { (Degrees) }\end{array}$ & $\begin{array}{c}\mathbf{C} \boldsymbol{\alpha}_{\mathbf{i}} \\
(\mathbf{d e g r e e s})\end{array}$ & $\begin{array}{c}\mathbf{S} \boldsymbol{\alpha}_{\mathbf{i}} \\
(\mathbf{d e g r e e s})\end{array}$ \\
\hline 1 & 125 & 0 & 0 & $\theta_{1}$ & $\theta_{1}$ & 1 & 0 \\
\hline 2 & 125 & 0 & 0 & $\theta_{2}$ & $\theta_{2}$ & 1 & 0 \\
\hline 3 & 5 & 0 & 0 & $\theta_{3}$ & $\theta_{3}$ & 1 & 0 \\
\hline
\end{tabular}

\section{KINEMATIC ANALYSIS}

\section{Direct Kinematics}

The link transformation matrices are as follows.

$$
\begin{aligned}
& { }_{1}^{0} T=\left[\begin{array}{cccc}
C_{1} & -S_{1} & 0 & L_{1} C_{1} \\
S_{1} & C_{1} & 0 & L_{1} S_{1} \\
0 & 0 & 1 & 0 \\
0 & 0 & 0 & 1
\end{array}\right] \\
& { }_{2}^{1} T=\left[\begin{array}{cccc}
C_{2} & -S_{2} & 0 & L_{2} C_{2} \\
S_{2} & C_{2} & 0 & L_{2} S_{2} \\
0 & 0 & 1 & 0 \\
0 & 0 & 0 & 1
\end{array}\right]
\end{aligned}
$$




$$
{ }_{3}^{2} T=\left[\begin{array}{cccc}
C_{3} & -S_{3} & 0 & L_{3} C_{3} \\
S_{3} & C_{3} & 0 & L_{3} S_{3} \\
0 & 0 & 1 & 0 \\
0 & 0 & 0 & 1
\end{array}\right]
$$

Overall transformation matrix

$$
{ }_{3}^{0} T={ }_{1}^{0} T \times{ }_{2}^{1} T \times{ }_{3}^{2} T
$$$$
{ }_{3}^{0} T={ }_{1}^{0} T \times{ }_{2}^{1} T \times_{3}^{2} T=\left[\begin{array}{cccc}
C_{3} C_{12}-S_{3} S_{12} & -C_{3} S_{12}-S_{3} C_{12} & 0 & L_{2} C_{3} C_{12}+L_{1} C_{1} C_{3}-L_{2} S_{3} C_{12}+L_{2} S_{2} S_{3}+L_{3} S_{3} \\
S_{3} C_{12}+C_{3} S_{12} & -S_{3} S_{12}+C_{3} C_{12} & 0 & L_{2} S_{3} C_{12}+L_{1} C_{1} S_{3}+L_{2} C_{3} C_{12}+L_{2} S_{2} C_{3}+L_{3} S_{3} \\
0 & 0 & 1 & 0 \\
0 & 0 & 0 & 1
\end{array}\right]
$$

At home position, consider $\theta_{1}=\theta_{2}=\theta_{2}=0$

In the direct kinematic model, the orientation and position of leg

$$
T_{E}=\left[\begin{array}{cccc}
n_{x} & o_{x} & a_{x} & d_{x} \\
n_{y} & o_{y} & a_{y} & d_{y} \\
n_{z} & o_{z} & a_{z} & d_{z} \\
0 & 0 & 0 & 1
\end{array}\right]=\left[\begin{array}{cccc}
1 & 0 & 0 & L_{2}+L_{1} \\
0 & 1 & 0 & L_{2} \\
0 & 0 & 1 & 0 \\
0 & 0 & 0 & 1
\end{array}\right]
$$

\section{Inverse Kinematics}

From the above transformation matrix equations, overall transformation matrix can be obtained. The required angles can be obtained by equating overall transformation matrix to the position and orientation matrix.

$$
\text { i.e. } T=\left[\begin{array}{cccc}
r_{11} & r_{12} & r_{13} & r_{14} \\
r_{21} & r_{22} & r_{23} & r_{24} \\
r_{31} & r_{32} & r_{33} & r_{34} \\
0 & 0 & 0 & 1
\end{array}\right]
$$

Then the following equations are obtained i.e.

$$
\begin{aligned}
& n_{14}=L_{2} C_{3} C_{12}-L_{2} S_{2} C_{12}+L_{1} C_{1}+L_{2} S_{2}+L_{3} S_{3} \\
& n_{24}=L_{2} S_{3} C_{12}-L_{2} S_{3} C_{12}+L_{1} C_{1}+L_{2} S_{2}+L_{3} S_{3}
\end{aligned}
$$

By dividing eq. 7 and eq. 8

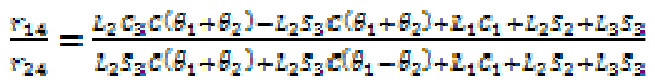

From the above equation

$$
\theta_{2}=\tan ^{-1}\left(\frac{r_{24}}{r_{14}}\right)
$$


For obtaining the other two angles inverse transformation of ${ }_{3}^{2} T$

i.e.

$$
\left[{ }_{3}^{2} T\right]^{-1}=\left[\begin{array}{cccc}
c_{3} r_{11}-s_{3} r_{12} & s_{3} r_{11}+c_{3} r_{12} & r_{13} & -L_{3} r_{11}+r_{14} \\
c_{3} r_{21}-s_{3} r_{22} & s_{3} r_{21}-s_{3} r_{22} & r_{23} & -L_{3} r_{21}-s_{3} r_{24} \\
c_{3} r_{31}-s_{3} r_{32} & s_{3} r_{31}-s_{3} r_{32} & r_{32} & -L_{3} r_{31}-s_{3} r_{34} \\
0 & 0 & 0 & 1
\end{array}\right]
$$

Equating eq.5 and eq. 11

$$
\begin{aligned}
& {\left[\begin{array}{cccc}
C_{12} & -S_{12} & 0 & L_{2} C_{12}+L_{1} C_{1} \\
S_{12} & C_{12} & 0 & L_{2} C_{12}+L_{2} S_{2} \\
0 & 0 & 1 & 0 \\
0 & 0 & 0 & 0
\end{array}\right]=\left[\begin{array}{cccc}
c_{3} r_{11}-s_{3} r_{12} & s_{3} r_{11}+c_{3} r_{12} & r_{13} & -L_{3} r_{11}+r_{14} \\
c_{3} r_{21}-s_{3} r_{22} & s_{3} r_{21}-s_{3} r_{22} & r_{23} & -L_{3} r_{21}-s_{3} r_{24} \\
c_{3} r_{31}-s_{3} r_{32} & s_{3} r_{31}-s_{3} r_{32} & r_{32} & -L_{3} r_{31}-s_{3} r_{34} \\
0 & 0 & 0 & 1
\end{array}\right]} \\
& L_{2} C_{12}+L_{1} C_{1}=L_{3} r_{11}+r_{14} \\
& -L_{2} C_{12}+L_{2} S_{2}=L_{2} r_{21}+r_{24}
\end{aligned}
$$

Adding both the above equations

$$
Z_{2} C_{12}+L_{1} C_{1}-L_{2} C_{12}+L_{2} S_{2}=L_{2} r_{11}+r_{14}+L_{2} r_{21}+r_{24}
$$

Assuming $\theta_{2}=0$ in eq.15, the equation for $\theta_{1}$ is obtained

$$
\begin{aligned}
& \text { i.e. } \theta_{1}=\cos ^{-1}\left(\frac{L_{3} r_{11}+r_{14}+L_{3} r_{21}+r_{24}}{L_{2}+L_{2}}\right) \\
& \theta_{2}=\theta_{1}-\cos ^{-1}\left(\frac{L_{3} r_{11}-z_{2} r_{21}+r_{24}}{L_{2}}\right)
\end{aligned}
$$

Final coordinates obtained by substituting the values in the above equations provide the solution as given below.

At home position i.e. $(250,0,0)$

$$
\begin{aligned}
& \theta_{1}=\cos ^{-1}\left(\frac{L_{3} r_{11}+r_{14}+L_{2} r_{21}+r_{24}}{L_{2}+L_{1}}\right)=0 \\
& \theta_{2}=\theta_{1}-\cos ^{-1}\left(\frac{L_{2} r_{11}-L_{2} r_{21}+r_{24}}{L_{2}}\right)=0 \\
& \theta_{3}=\tan ^{-1}\left(\frac{r_{24}}{r_{14}}\right)=0
\end{aligned}
$$

End point $\mathrm{P}$ position at 1 i.e. $(210,75$, and 0$)$

$$
\begin{aligned}
& \theta_{1}=\cos ^{-1}\left(\frac{L_{2} r_{11}+r_{14}+L_{2} r_{21}+r_{24}}{L_{2}+L_{1}}\right)=49 \\
& \theta_{2}=\theta_{1}-\cos ^{-1}\left(\frac{L_{2} r_{11}-L_{2} r_{21}+r_{34}}{L_{2}}\right)= \pm 57
\end{aligned}
$$




$$
\theta_{2}=\tan ^{-1}\left(\frac{r_{24}}{n_{14}}\right)=19
$$

End point $\mathrm{P}$ position at 2 i.e. $(220,85$, and 0$)$

$$
\begin{aligned}
& \theta_{1}=\cos ^{-1}\left(\frac{L_{2} r_{11}+r_{14}+L_{2} r_{21}+r_{24}}{L_{2}+L_{1}}\right)=43 \\
& \theta_{2}=\theta_{1}-\cos ^{-1}\left(\frac{L_{2} r_{11}-L_{2} r_{21}+r_{24}}{L_{2}}\right)= \pm 45 \\
& \theta_{2}=\tan ^{-1}\left(\frac{r_{24}}{r_{14}}\right)=20.77
\end{aligned}
$$

\section{INVERSE KINEMATICS USING ROBO-ANALYSER SOFTWARE}

In order to validate the theoretical results obtained, the kinematics of the robot leg structure is performed in a Robo-Analyser software.

\section{D-H Representation Using Robo-Analyser Software}

Figure 3 represent the D-H parameters of the link between joint 2 and joint 3. Figure 4, 5 and 6 shows inverse kinematics of leg structure at standalone, end position P1 and end position P2 respectively.

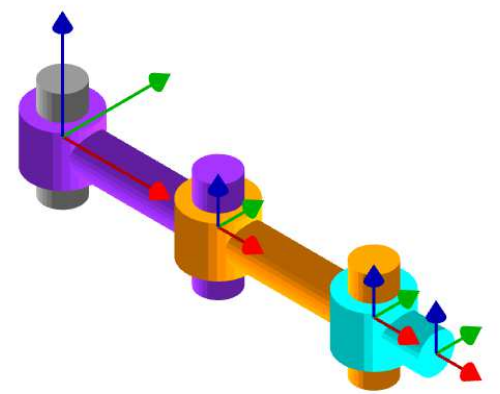

Figure 3: D-H Parameters of the Link between the Joint 2 and Joint 3

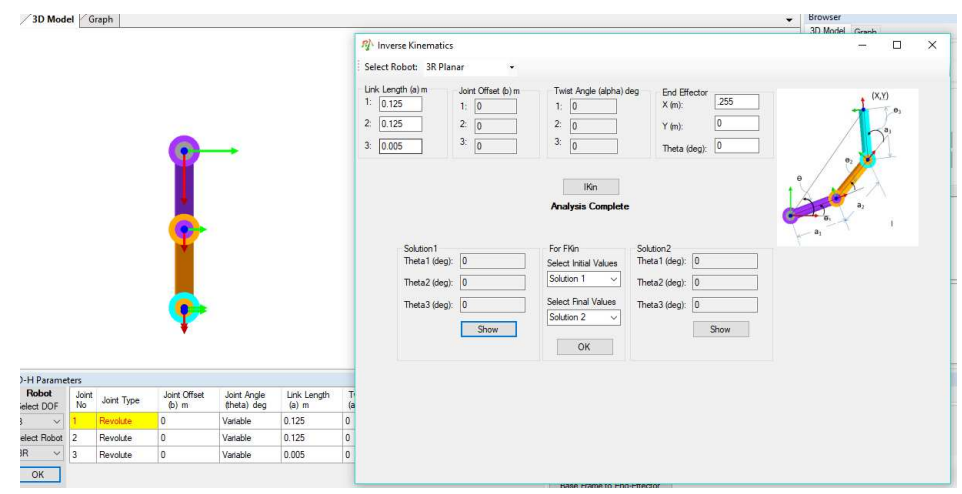

Figure 4: Inverse kinematics at Standalone Position 


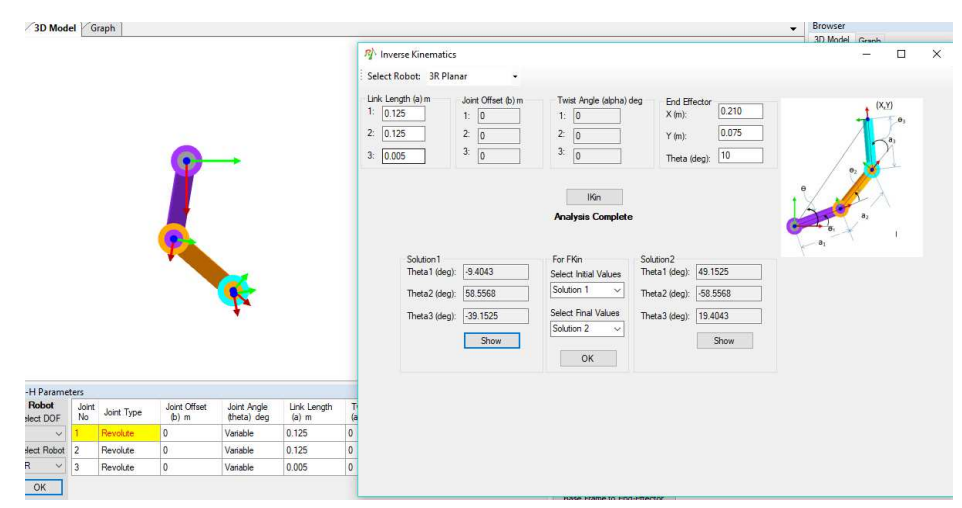

Figure 5: Results of Inverse Kinematics at Position P1

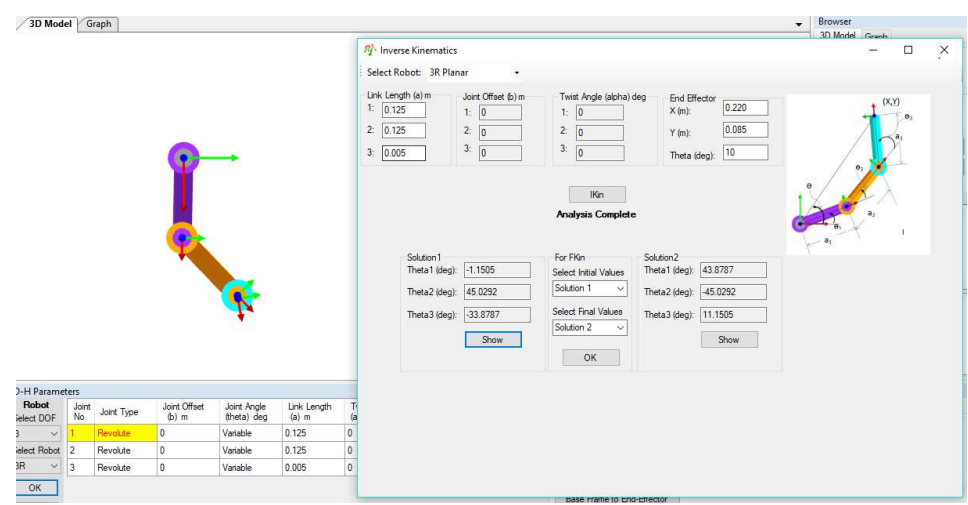

Figure 6: Results of Inverse Kinematics at Position P2

\section{COMPARISON OF RESULTS}

Results obtained using the theoretical kinematic analysis and Robo-Analyzer software analysis are presented in Table 8. It can be seen that manipulator positions, coordinates obtained at various locations are almost same and thus validate the proposed design model.

Table 8: Comparison of Theoretical and Software Results

\begin{tabular}{|c|c|c|}
\hline At different Positions & $\begin{array}{c}\text { Inverse Kinematics Theoretical } \\
\text { Solutions }(\mathbf{x}, \mathbf{y}, \mathbf{z})\end{array}$ & $\begin{array}{c}\text { Using Robo-Analyser software } \\
\text { Solutions }(x, y, z)\end{array}$ \\
\hline At home position $(250,0,0)$ & $(0,0,0)$ & $(0,0,0)$ \\
\hline End point $\mathrm{P}$ position at $1(210,75,0)$ & $(49, \pm 57,19)$ & $(49.5, \pm 58,19.4)$ \\
\hline End point $\mathrm{P}$ position at $2(220,85,0)$ & $(43, \pm 45,21)$ & $(44, \pm 45,25.7)$ \\
\hline
\end{tabular}

\section{CONCLUSIONS}

This paper presents the design of a quadruped robot, having four legs but based on human leg structure and its kinematic analysis. Following conclusions are drawn from the work. Selection of legged robot configuration i.e., bipedal robot was made based on its advantages over other configurations. A detailed study of various parameters amongst mammals was made to finalize the locomotion style in the proposed quadruped robot. It is found that the locomotion stylewalking of humans and horses is almost same. Further study was made, to finalize the human locomotion style. Various conceptual designs of leg structure were prepared, in Creo software. Based on the characteristics and other aspects, less complex and more reliable design was selected (Third design). This design improved gait, gave better stability and avoids collision of two legs, during motion. Both theoretical and simulated inverse kinematic analysis, of quadruped robot based on bipedal leg structure, was carried out using D-H method. Robo-Analyser software was used, for performing the analysis 
in software. Results obtained using theoretical and simulated analysis validated the design model, proposed at the end position's results, of the manipulator were almost same.

\section{REFERENCES}

1. M. Z. A. Rashid, M. S. M. Aras, A. A. Radzak, A. M. Kassim, and A. Jamali (2012), "Development of Hexapod Robot with Manoeuvrable Wheel”, International Journal of Advanced Science and Technology, Vol. 49

2. Bhawana, D. Parate, Jagruti J Shah (2014), “Design and Development of Multifunctional Robot for Military Purpose Applications", International journal of Engineering Research and Application, ISSN: 2248-9622.

3. Giuseppe Carbone \& Marco Ceccarelli (2005), "Legged Robotic Systems” Edge Robotics, ISBN 3-86611-038-3, pp. 784

4. Seong Chiun Lim, Gik Hong Yeap (2012), "The Locomotion of Bipedal Walking Robot with Six Degree of Freedom" International Symposium on Robotics and Intelligent Sensors 2012, Procedia Engineering 41

5. G.V. Phani Babu \& N. Amara Nageswara Rao (2012), "Design and Analysis of a Low Cost and Easy Operated Leg Mechanism for A Walking Robot”, International Journal of Mechanical and Industrial Engineering (IJMIE), ISSN No. 2231 6477, Vol-2, Issue-1,

6. Oren Y. Kanner, Aaron M. Dollar (2012), “Kinematic Design of an Underactuated Robot Leg for Passive Terrain Adaptability and Stability”, JMR-12-1115

7. Limei Liu, Hong Jiang, Jianfei Li, Yantao Tian, Mao Yang (2012), “Adaptive Excitation Control for the Underactuated Biped Robot” International Conference on Future Electrical Power and Energy Systems, Energy Procedia 17 (2012) PP 1667 1674.

8. Christian Gehringy, Stelian Corosy, Marco Hutter, Michael Bloesch, Markus A. Hoepflinger and Roland Siegwart (2013), “Control of Dynamic Gaits for a Quadrupedal Robot” IEEE International Conference on Robotics and Automation

9. Marco Hutter, Christian Gehring, Michael Bloesch, Mark Hoepinger and Roland Siegwart (2013), "Walking and Running with StarlETH” The 6th International Symposium on Adaptive Motion of Animals and Machines (AMAM), March 11-14

10. Marco Hutter, Christian Gehring, Michael Bloesch, Mark A. Hoepflinger, C. David Remy, And Roland Siegwart (2012), “StarlETH: A Compliant Quadrupedal Robot for Fast, Efficient, And Versatile Locomotion” WSPC-Proceedings, April 5,

11. Mark A. Hoepflinger, C. David Remy, Marco Hutter, Luciano Spinello, and Roland Siegwart (2010), "Haptic Terrain Classification for Legged Robots" 2010 IEEE International Conference on Robotics and Automation, Anchorage Convention District 
